Narrativa

\title{
Ezio PUGLIA, Il lato oscuro delle cose. Archeologia del fantastico e dei suoi oggetti
}

\section{Stefano Lazzarin}

\section{(2) OpenEdition \\ 1 Journals}

Edizione digitale

URL: https://journals.openedition.org/narrativa/493

DOI: $10.4000 /$ narrativa.493

ISSN: 2804-1224

Editore

Presses universitaires de Paris Nanterre

\section{Edizione cartacea}

Data di pubblicazione: 1 décembre 2021

Paginazione: 303-305

ISBN: 978-2-84016-485-2

ISSN: $1166-3243$

\section{Notizia bibliografica digitale}

Stefano Lazzarin, «Ezio puglı, Il lato oscuro delle cose. Archeologia del fantastico e dei suoi oggetti», Narrativa [Online], 43 | 2021, online dal 01 novembre 2021, consultato il 03 novembre 2022. URL: http://journals.openedition.org/narrativa/493 ; DOI: https://doi.org/10.4000/narrativa.493

Questo documento è stato generato automaticamente il 3 novembre 2022.

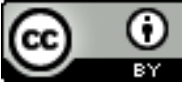

Creative Commons - Attribuzione 4.0 Internazionale - CC BY 4.0

https://creativecommons.org/licenses/by/4.0/ 


\title{
Ezio PUGLIA, Il lato oscuro delle cose. Archeologia del fantastico e dei suoi oggetti
}

\author{
Stefano Lazzarin
}

\section{NOTIZIA}

Ezio PUGLIA, Il lato oscuro delle cose. Archeologia del fantastico e dei suoi oggetti, postfazione di Angelo M. Mangini, Modena, Mucchi, 2020, 320 p.

1 Da un quarto di secolo a questa parte, i migliori libri sulla letteratura fantastica - e sul fantastico italiano - pubblicati in Italia sono venuti da studiosi che o si sono formati a Bologna, o vi hanno lavorato per lunghi periodi, o entrambe le cose: penso ai nomi di Ceserani, Roda, Amigoni, Mangini, Weber. Alla lista viene ora ad aggiungersi l'autore di questo volume, degno erede di quella che può essere descritta come una tradizione di studi consolidata e caratterizzata da tratti comuni - uno fra tutti, il rigore storico, teorico, metodologico.

2 Come gli specialisti più avvertiti, Puglia conferisce al termine "fantastico" un preciso significato storico-letterario: la letteratura fantastica è quel "genere storico [...] che si è formato [nell'Ottocento] [...] sull'onda dello straordinario successo delle opere di E.T.A. Hoffmann". Il lato oscuro delle cose si inscrive così, oltreché nella "scuola bolognese" cui accennavo, nella migliore tradizione teorica sulla letteratura fantastica: quella degli studiosi che non vedono nel fantastico un fenomeno metastorico di tutte le epoche e di tutti i luoghi, e ancor meno ne fanno l'incarnazione letteraria di una facoltà dello spirito umano come la fantasia o l'immaginazione, ma che lo collocano in una serie di contesti - letterari, storici, culturali, linguistici - ben definiti. Al tempo stesso Puglia apporta alla rappresentazione che del fantastico hanno offerto i vari Caillois e Todorov, Ceserani e Lugnani una serie di correttivi, ridiscutendo intelligentemente - e a volte mutandone radicalmente il senso - rilievi e connessioni che ci eravamo abituati a 
considerare come assodati: dall'autocoscienza del fantastico al ruolo canonico dei grandi maestri ottocenteschi Hoffmann e Poe, e dalla nozione di "modo fantastico" a quella di "fantasticizzazione".

3 Ma più che gli aspetti teorici, quel che colpisce nel Lato oscuro delle cose è la corposa concretezza storica dell'indagine sul fantastico e sui suoi oggetti. Puglia sceglie infatti di "ascoltare il più possibile gli stessi autori attraverso le cui opere e riflessioni il fantastico, come autonomo genere narrativo, ha preso forma, oltre che alcuni critici loro contemporanei": il suo è un fantastico che non assomiglia più al simulacro teorico, magari geometrico e di cristallina limpidezza, ma fin troppo astratto, degli strutturalisti; bensì risulta immerso nella vivacità delle battaglie letterarie, delle prefazioni e dei racconti tradotti e travisati, delle dichiarazioni d'autore e degli scambi intellettuali. Quello che Puglia ci mette sotto gli occhi è, di nuovo, un genere risolutamente storico: di cui il critico ricostruisce la vicenda complessa e possiamo ben dire avventurosa con eccezionale sensibilità per le sue connessioni con la storia, la società, la cultura, l'immaginario, il linguaggio e le idee delle varie epoche e aree geografiche.

4 Resta da dire degli oggetti che campeggiano nel titolo del volume. Prima di Puglia si sapeva, sì, che l'oggettualità del fantastico è importantissima; ma lo si sapeva quasi esclusivamente grazie al saggio di Lugnani sugli oggetti mediatori e al volume di Orlando sugli oggetti desueti: ovvero due ricerche di grande valore e due topoi assolutamente decisivi, ma per l'appunto soltanto due. Puglia invece - pur rifuggendo dalla casistica, e avvisando il lettore che non stilerà nessun "elenco esaustivo delle cose auratiche e spettrali del fantastico ottocentesco" - ci fa discernere e apprezzare i mille volti, spesso affascinanti, delle cose descritte nei racconti e nei romanzi fantastici: oggetti inquietanti, assurdi, erotici, da collezione; feticci, reliquie, indizi, rifiuti; oggetti surreali, alieni, spettrali e auratici (secondo la bipartizione principale, abbozzata alle pp.11-12); e via di seguito. E grazie al punto di osservazione costituito dalla rappresentazione letteraria degli oggetti, getta nuova luce su molti capolavori del fantastico otto-novecentesco che ci illudevamo di conoscere a menadito.

In sintesi: Il lato oscuro delle cose è destinato a occupare un posto nello scaffale dei libri di più feconda consultazione per chi si interessa al fantastico, non solo nelle vesti di studioso, ma anche di lettore appassionato. E ne consiglio senza esitare la lettura agli specialisti di vari altri campi - comparatisti e teorici, studiosi degli oggetti e seguaci della thing theory - nonché a chiunque sia curioso di letteratura otto- e novecentesca. 